Rotherham District General Hospital, Moorgate Road,

Oakwood,

Rotherham S60 2UD

\section{Fibre and enteral nutrition}

SIR, - We read with great interest Dr Silk's review, but we were surprised at the omission of any detail on the effects of enteral nutrition on cholesterol metabolism. In our own experimental studies, ${ }^{2}$ rats fed for 10 weeks with Vivonex develop severe fatty infiltration of the liver, similar to Kwashiorkor, with initial deposition of fat in the periportal regions with progressive involvement around the central vein with significant quantitative increases in total liver lipid and cholesterol. No such changes were detectable in the livers of animals fed for 10 weeks with Vivonex which was supplemented with $5 \%$ wheat bran. The accumulation of lipids and cholesterol in the livers of rats fed Vivonex has been reported by others. ${ }^{3+} \mathrm{We}$ concluded that dietary bran thus appears to play a role in maintaining normal lipid metabolism and suggest that caution be exercised in those patients on longterm enteral feeding with careful monitoring of blood lipids.

M R LEWIN AND A P JAYARAJ

Department of Surgery,

The Rayne Institute,

University Street,

London WC1E 6JJ

\section{References}

1 Silk DBA. Fibre and enteral nutrition. Gut 1989; 30: 246-64.

2 Jayaraj AP, Barton T, Lewin MR, Clark CG. Kwashiorkor-like liver changes induced by an elemental diet can be prevented with dictary wheat bran. [Abstract] Gut 1985; 26: A522-3.

3 Nelson LM, Williamson I, Russell RI. Elemental diet composition: effect on bile acid metabolism and hepatic lipids. [Abstract] Gut 1981; 22: A429-30.

4 Park RHR, Duncan A, Mitchell G, East W, Russell RI. Comparison of modular elemental and poymeric liquid diets on growth, nitrogen $(\mathrm{N})$ balance, $\mathrm{N}$ wastage, faecal residue and hepatic lipids in rats. [Abstract] Gut 1985; 26: A1112.

\section{Reply}

SIR, - I would like to thank Drs Lewin and Jayaraj for their helpful comments about my Progress Report Fibre and enteral nutrition. They are correct in that I did omit details about the fact that it is well known that feeding rats with Vivonex results in severe fatty infiltration of the liver. My literature search failed to reveal results of their experiment showing that the supplementation of Vivonex with 5\% wheat bran prevents these changes from developing. I apologise for this. The reason is that their data are as far as I am aware are only published in Abstract form (Gut 1985; 26: A522-3).

D B A SILK

Department of Gastroenterology and Nutrition, Central Middlesex Hospital,

London NWIO

\section{Books}

Gastroenterologic endoscopy. Edited by M V Sivak Jr. (Pp. 1168; illustrated; £95.) Philadelphia: Saunders, 1987.

This is the most impressive textbook yet on gastrointestinal endoscopy. It is certainly the longest at 1168 pages and the heaviest, tipping the scales at $3 \cdot 28$ $\mathrm{kg}$. It is also pricey, costing $£ 95$. Is it the best? I think so.

It is written in the style of the classic Saunders American textbook of medicine with 48 chapters contributed by 75 contributors. The chapters are written in academic fashion and are well laced with references, some chapters having more than 150 . In an effort to keep pace with advances since the chapters were written, the editor has added the occasional footnote with additional recent key references.

The account of fibreoptic instrument technology was made transparently clear by the quality of the line drawn diagrams. The chapters teaching how to do it; upper GI endoscopy, choledochofibrescopy, colonoscopy, flexible sigmoidoscopy and laparoscopy are very clear. A special methods section ranged from a chapter showing the beauty of the arcane specialty of chromoscopy, through peroral cholangioscopy and pancreatoscopy (a master and subendoscope system somehow sounds less attractive than a mother and baby endoscope) to endoscopic ultrasonography, videoendoscopy, gastrostomy to high magnification endoscopy. It is backed by good didactic chapters on the extraordinary range of pathology now to be viewed at endoscopy throughout the bowel. The oesophageal chapters were excellent as were surprising chapters on postoperative endoscopy, emergency laparoscopy and the differential diagnosis of inflammatory and infectious colitis. The 
quality of the text is high in most areas and the illustrations are of above average quality. The sections on ERCP and its ramifications were particularly well done with the best how to do it account in words of an endoscopic technique that I have read but also backed up by marvellously erudite chapters on the anatomy and embryology of the pancreas and biliary system and on the sphincter of Oddi.

It is comprehensive as a textbook of this length should be and is generally well balanced. Minor criticisms that might be considered for correction in a future edition are two: there is no section on rigid sigmoidoscopy which seems an omission as the cheapness and convenience of this tool with the recent advent of the transparent disposable sigmoidoscope suggests that rigid sigmoidoscopes are not going to be replaced by flexible sigmoidoscopes at least for some time. There is a whole chapter on dilatation of biliary strictures but only a couple of pages on dilating the oesophagus.

This book is a considerable achievement. It enhances a view of endoscopy as a subject worthy of scientific and academic respectability and manages to be both authoritatively learned and practical as a handbook. Gastrointestinal endoscopy has come of age.

PAUL SWAIN

A colour atlas of the digestive system. By $R$ E Pounder, M C Allison, and A P Dhillon. (Pp. 232; illustrated; £30.) London: Wolfe Medical, 1988.

The phenomenon of the 'coffee table' textbook glossy, profusely illustrated and minimally textual - is somewhat mystifying; for whom are these books written and who buys them? The authors have aimed to provide '. . . a wealth of clear illustrations to . . . thus complement a standard textbook of gastroenterology such as Diseases of the gut and pancreas edited by $\mathbf{J} \mathbf{J}$ Misiewicz, R E Pounder, and $\mathrm{C} \mathrm{W}$ Venables (Blackwell Scientific Publications, 1987)'. Well, there's no harm in a little advertising, but one can't help wondering why the colour illustrations weren't inserted in the textbook itself; presumably, the cost of the combined volume would be about the same as these two volumes together. The book is certainly too expensive for undergraduates and, one would suspect, of limited appeal to postgraduates. Still, the publishers must know what they are about, as they have produced a profusion of similar volumes, and are still in business.

That being said, the 636 illustrations have been chosen and printed with care, and the book does provide a good overview of gastroenterology for . . . for people who like this kind of thing. Do not, however, make the mistake of leaving it on your coffee table at home; the colour is vivid, and the illustrations are not for the faint hearted.

DAVID WINGATE

An endoscopic approach to bilio-pancreatic disease. By Luigi Familiari. Translated by Antonio Borruto. (Pp. 196; illustrated; £33.) Padua, Italy: Piccin Nuova Libreria, 1988.

This Italian work in English translation gives a descriptive account of endoscopic retrograde cholangiopancreatography and related therapeutic techniques and their application to the diagnosis and treatment of common biliary and pancreatic disorders. The foreward, by Claude Liguory, with whom the author once worked, commends the book on the basis that 'A picture is worth a thousand words', invoking an analogy between endoscopy in general and this book in particular. There are 123 figures, of which the majority are radiographs. The comment is also made that this book presents 'A complete and yet simple treatment of new knowledge in bilio-pancreatic pathology'. Unfortunately, I cannot agree that this book is complete in the comprehensive sense but do agree that this is a relatively simple view of the techniques involved and thereby suggest that this text is aimed at the novice, who has not previously been exposed to ERCP in any way. When read on this basis, the book, provides a suitable introduction to the subject although the inevitable unintended false interpretations and meanings result from the English translation of the original Italian text. The eight chapters include descriptions of basic embryology and anatomy, instrumentation, diagnostic ERCP, biliary pathology, pancreatic pathology, contra-indications and complications of the techniques, endoscopic sphincterotomy and, finally, direct choledochoscopy and pancreatoscopy. All topics, however, are dealt with in a basic way with sometimes very brief descriptions. Some of the endoscopic photographs are rather poor and radiographs would have been improved by suitable labelling, considering that many readers will not be familiar with them. Some of the line drawings of techniques are helpful and perhaps more could have been made of this in explanations of radiographs. Each chapter is reasonably well referenced, but there is a curious lack of references after 1982 which, together with some of the views expressed in the book, make one think that the text was written some years ago and perhaps has taken some considerable time to be published. In this sense therefore it is not an up-to-date work and particularly the chapter on instrumentation is extremely limited to one manufacturer and even then not all currently available instruments are included. 